\title{
Psychometric validation of patient-reported outcome measures assessing chronic constipation
}

This article was published in the following Dove Press journal:

Clinical and Experimental Gastroenterology

26 September 2014

Number of times this article has been viewed

\author{
Lauren M Nelson' \\ Valerie SL Williams' \\ Sheri E Fehnel' \\ Robyn T Carson ${ }^{2}$ \\ James MacDougall ${ }^{3}$ \\ Mollie J Baird ${ }^{3}$ \\ Stavros Tourkodimitris ${ }^{2}$ \\ Caroline B Kurtz ${ }^{3}$ \\ Jeffrey M Johnston ${ }^{3}$ \\ 'RTI Health Solutions, Durham, NC, \\ USA; ${ }^{2}$ Forest Research Institute, \\ Jersey City, NJ, USA; ${ }^{3}$ Ironwood \\ Pharmaceuticals, Cambridge, MA, USA
}

Correspondence: Valerie SL Williams RTI Health Solutions, 3040 Cornwallis Road, PO Box 12194, Research Triangle Park, NC 27709, USA

Tel + I 9193163820

Fax + I 919 54I 7222

Email vwilliams@rti.org
Background: Measures assessing treatment outcomes in previous CC clinical trials have not met the requirements described in the US Food and Drug Administration's guidance on patientreported outcomes.

Aim: Psychometric analyses using data from one Phase IIb study and two Phase III trials of linaclotide for the treatment of chronic constipation (CC) were conducted to document the measurement properties of patient-reported CC Symptom Severity Measures.

Study methods: Each study had a multicenter, randomized, double-blind, placebo-controlled, parallel-group design, comparing placebo to four doses of oral linaclotide taken once daily for 4 weeks in the Phase IIb dose-ranging study $(n=307)$ and to two doses of linaclotide taken once daily for 12 weeks in the Phase III trials $(n=1,272)$. The CC Symptom Severity Measures addressing bowel function (Bowel Movement Frequency, Stool Consistency, Straining) and abdominal symptoms (Bloating, Abdominal Discomfort, Abdominal Pain) were administered daily using interactive voice-response system technology. Intraclass correlations, Pearson correlations, factor analyses, $F$-tests, and effect sizes were computed.

Results: The CC Symptom Severity Measures demonstrated satisfactory test-retest reliability and construct validity. Factor analyses indicated one factor for abdominal symptoms and another for bowel symptoms. Known-groups $F$-tests substantiated the discriminating ability of the CC Symptom Severity Measures. Responsiveness statistics were moderate to strong, indicating that these measures are capable of detecting change.

Conclusion: In large studies of CC patients, linaclotide significantly improved abdominal and bowel symptoms. These psychometric analyses support the reliability, validity, discriminating ability, and responsiveness of the CC Symptom Severity Measures for evaluating treatment outcomes in the linaclotide clinical studies.

Keywords: psychometric evaluation, patient-reported outcomes, linaclotide

\section{Introduction}

Chronic constipation (CC) is a functional bowel disorder that affects approximately $15 \%$ of the North American population ${ }^{1}$ and is characterized by infrequent bowel movements (BMs) and other associated symptoms (ie, hard and lumpy stools, straining during defecation, a sensation of incomplete evacuation, and bloating). As with other functional bowel disorders, there is not an identifiable organic pathology responsible for the bowel disturbances seen in $\mathrm{CC}$, and outcomes of treatment for $\mathrm{CC}$ are assessed through direct patient report or patient-reported outcomes (PROs). PRO measures that are intended for use as primary or key secondary endpoints in clinical trials should be developed and psychometrically evaluated in accordance with recommendations set forth in the US Food and Drug Administration's (FDA's) guidance, Patient-Reported 
Outcome Measures: Use in Medical Product Development to Support Labeling Claims. ${ }^{2}$ To our knowledge, none of the PRO measures used to assess CC symptom severity in previously published clinical trials meet the development requirements described in the FDA's PRO guidance. Specifically, there is no published evidence to suggest that these measures were developed with patient input, address all CC symptoms of importance to patients, and were psychometrically validated in a CC patient population. To address this gap, a set of patient-reported measures, the CC Symptom Severity Measures, was developed based on a synthesis of relevant literature and interviews with $\mathrm{CC}$ patients, and in accordance with the FDA's PRO guidance, to assess the severity of both bowel and abdominal symptoms important to patients with $\mathrm{CC}$.

The objectives of the present study were to evaluate and document the psychometric properties of the CC Symptom Severity Measures in one Phase IIb study and two Phase III clinical trials of linaclotide in CC patients.

\section{Methods}

\section{Study design}

The psychometric properties of the CC Symptom Severity Measures were initially evaluated using data from a Phase IIb clinical study of linaclotide, and confirmed using data from two Phase III clinical trials of linaclotide, a minimally absorbed peptide agonist of the intestinal guanylate cyclase type- $\mathrm{C}$ receptor. Details of the trial designs have been published previously. ${ }^{3,4}$ These studies were reviewed and approved by the appropriate ethics committees at the participating centers, and approvals were obtained prior to any subject's participation. All study subjects provided written informed consent.

\section{Phase Ilb}

Data from a randomized, multicenter, double-blind, placebocontrolled, dose-range-finding, parallel-group Phase IIb clinical study comparing placebo and four doses of oral linaclotide $(75 \mu \mathrm{g}, 150 \mu \mathrm{g}, 300 \mu \mathrm{g}$, or $600 \mu \mathrm{g})$ taken once daily were analyzed to assess the psychometric properties of the CC Symptom Severity Measures. (Based on improved methods used to measure linaclotide content, dosing conventions for linaclotide vary across published studies. However, these variations do not reflect a change in the actual amount of linaclotide used in clinical trials. The $145 \mu \mathrm{g}$ and $290 \mu \mathrm{g}$ designations are the approved dosing conventions for linaclotide ${ }^{5}$ ). A total of 310 adult patients with CC were randomized to one of five treatment groups, with approximately
60 patients in each treatment group. The design included a 2-week pretreatment period (baseline) followed by 4 weeks of treatment (treatment period) and 2 weeks of posttreatment follow-up. The psychometric analyses included all intent-totreat subjects $(n=307)$.

\section{Phase III}

Data from two randomized, multicenter, double-blind, placebo-controlled, parallel-group Phase III clinical trials comparing placebo and two doses of oral linaclotide taken once daily were used to confirm the psychometric properties of the CC Symptom Severity Measures. The two clinical trials included 630 and 642 adult patients with CC randomized to one of three groups (placebo, oral linaclotide $145 \mu \mathrm{g}$, or $290 \mu \mathrm{g})$. Both trials included a 2 -week pretreatment period (baseline) followed by a 12-week treatment period. The psychometric analyses were performed on the pooled dataset of all intent-to-treat subjects $(n=1,272)$ from the 12 -week treatment period, which included 30 Spanish-speaking patients. In preparation for the inclusion of US-based Spanish-speaking participants in the Phase III trials, all study materials were translated into US Spanish, tested with patients, and certified as linguistically and culturally validated.

\section{Symptom Severity Measures}

Information used in the derivation of the CC Symptom Severity Measures was gathered via telephone-based interactive voice-response system (IVRS) technology. During a daily IVRS telephone call, patients were asked a series of questions pertaining to the frequency and timing of their BMs and use of per-protocol rescue medicines (bisacodyl tablet or suppository) or any other laxatives, suppositories, or enemas, as well as to the severity of bloating, abdominal discomfort, and abdominal pain on a 5-point ordered response scale ( $1=$ none, $2=$ mild, $3=$ moderate, $4=$ severe, $5=$ very severe). Weekly rates of Spontaneous BM (SBM) Frequency and Complete SBM (CSBM) Frequency were calculated. For each BM, patients were asked to describe stool consistency using the 7-point Bristol Stool Form Scale, ${ }^{6}$ to rate their straining (5-point scale), and to assess completeness of evacuation (yes or no). The daily IVRS-administered CC Symptom Severity Measures - Bloating, Abdominal Discomfort, and Abdominal Pain - were aggregated to describe average weekly severity, as were the two BM-specific items (Straining and Stool Consistency). The set of CC Symptom Severity Measures to be evaluated consisted of CSBM Frequency, SBM Frequency, Stool Consistency, Straining, Bloating, Abdominal Discomfort, and Abdominal Pain. 
The primary efficacy endpoint in the linaclotide trials, Overall CSBM Responder status, was based on CSBM Frequency and was used in the psychometric evaluation of the CC Symptom Severity Measures. Overall CSBM Responders were defined as those patients who reported at least three CSBMs per week and at least one more CSBM per week compared with baseline, in the same week, for at least 3 of 4 weeks of the Phase IIb treatment period, or at least 9 of 12 weeks of the Phase III treatment period.

\section{Additional validation measures}

The Patient Assessment of Constipation Quality of Life (PAC-QOL) ${ }^{7}$ is a comprehensive questionnaire assessing the burden of constipation on patients' everyday functioning and well-being. The PAC-QOL provides an overall score and four subscale scores - Worries and Concerns, Physical Discomfort, Psychosocial Discomfort, and Satisfaction. The PAC-QOL was completed by patients on day 1 prior to the first dose of study drug and during the last treatment period visit (ie, day 29 in Phase IIb; day 85 in Phase III) or early-termination visit.

Additionally, patients were asked weekly to rate the severity of their constipation during the past 7 days on a 5-point scale (Constipation Severity) and to rate their overall relief of CC symptoms compared to baseline on a 7-point balanced scale (Constipation Relief).

\section{Analytic methods}

All psychometric properties were investigated irrespective of treatment group using SAS for Windows (v 9.2; SAS Institute Inc., Cary, NC, USA). Exploratory factor analysis (EFA) and confirmatory factor analysis (CFA) were conducted using Mplus software (v 6.1; Muthén \& Muthén, Los Angeles, CA, USA). ${ }^{8}$

\section{Reliability}

To assess test-retest reliability, intraclass correlation coefficients (ICCs) were computed for each of the CC Symptom Severity Measures using data from the last 2 weeks of treatment, when patients' symptoms were assumed to be stable. In the Phase IIb study, the data averaged over the third week of the treatment period were the "test" administration and the data averaged over the fourth week of the treatment period were the "retest"; in the Phase III trials, the ICCs were computed using data from weeks 11 and 12. It is generally recommended that ICCs be at least 0.70 for multi-item scales. ${ }^{9}$ Because the CC Symptom Severity Measures are to be used only as individual items and are not intended to be scored together or summed as a multi-item scale, internal consistency reliability was not computed.

\section{Validity \\ Construct validity}

Specific inter-symptom relationships were hypothesized a priori among the CC Symptom Severity Measures. Correlations of 0.10 are considered small; correlations of 0.30 are considered moderate; and correlations of 0.50 or greater are considered large or strong. ${ }^{10}$ Evidence of construct validity was also hypothesized for the correlations between the weekly assessment of Constipation Relief and corresponding changes from baseline in the CC Symptom Severity Measures. Finally, correlations between the CC Symptom Severity Measures and the PAC-QOL were used to help demonstrate construct validity. Specifically, the change in PAC-QOL scores from day 1 to end of treatment was correlated with the change in the CC Symptom Severity Measures from baseline to the average over the last 2 weeks of treatment.

\section{Factor analysis}

EFA was used to determine the number of continuous latent variables (ie, factors) that optimally explain the correlations observed among the CC Symptom Severity Measures using data from the Phase IIb study. Maximum likelihood estimation was used and an oblique, specifically quartimin, rotation was applied, allowing the extracted factors to be correlated. Standard errors for the rotated solutions were used to test individual coefficients for significance. We anticipated a twodimensional structure, with bowel symptom measures loading on one factor and the abdominal symptom measures on the other factor. However, the final decision as to the number of factors was based on the size of the eigenvalues,,${ }^{11}$ the size and pattern of the factor loadings, and the interpretability of the factor(s). The item factor loadings (standardized regression coefficients) for the best-fitting solution are presented.

Models were proposed based on the Phase IIb EFA results and evaluated using CFA methods and data from the pooled Phase III trials. Criteria for model fit included the chi-square test, ${ }^{12}$ where a statistically nonsignificant value $(P>0.01)$ indicates model fit. The Comparative Fit Index ${ }^{13}$ and a non-normed fit index, the Tucker-Lewis index (TLI), ${ }^{14}$ were also applied to evaluate model fit; values greater than 0.95 are most desirable. ${ }^{15}$ In addition, the standardized root mean square residual (SRMR) is presented; values smaller than 0.08 are recommended. ${ }^{15}$

\section{Discriminating ability}

Analyses of variance examined mean differences in the CC Symptom Severity Measures between patients classified 
into groups based on 1) Overall CSBM Responder status and 2) the treatment period average of Constipation Severity (severe/very severe versus none/mild). It was predicted that scores would be statistically significantly better among patients classified as responders and among patients reporting milder constipation severity symptoms across the treatment period average, thereby providing evidence in support of the discriminating ability of the CC Symptom Severity Measures.

\section{Responsiveness}

To evaluate responsiveness, a variant of Guyatt's statistic ${ }^{16}$ was calculated to compare subgroups based on Overall CSBM Responder status (responders versus nonresponders) and Constipation Relief status (improved versus worsened). Computing change as treatment period average minus baseline, responsiveness was calculated as the difference in the mean change between the subgroups (ie, the mean difference between Overall CSBM Responders minus nonresponders; and the mean difference between completely/considerably improved minus worsened categories for Constipation Relief) divided by the standard deviation (SD) of the change in nonresponders or the SD of the change in the worsened subgroup. The resulting value is an effect size indicating a measure's ability to detect change in CC symptoms. Effect sizes of about 0.20 represent small effects; those of about 0.50 represent moderate effects; and those of 0.80 represent large effects. ${ }^{10}$

\section{Results}

Table 1 summarizes the characteristics of the study participants and baseline scores on the CC Symptom Severity Measures. The majority of participants in both the Phase IIb and Phase III trials were female and white.

\section{Reliability}

The test-retest ICCs for all CC Symptom Severity Measures exceeded the recommended 0.70 in the Phase IIb study analyses, except for Straining (0.68). In the Phase III study, the ICCs for the CC Symptom Severity Measures were highly satisfactory, ranging from 0.72 (Stool Consistency and Straining) to 0.89 (Bloating).

\section{Validity}

\section{Construct validity}

Table 2 presents the inter-item correlations among the CC Symptom Severity Measures and correlations with Constipation Severity computed using the Phase IIb and Phase III treatment
Table I Baseline demographics and characteristics of study participants

\begin{tabular}{|c|c|c|}
\hline Demographic/characteristic & $\begin{array}{l}\text { Phase Ilb } \\
\mathrm{N}=\mathbf{3 0 7}\end{array}$ & $\begin{array}{l}\text { Phase III } \\
N=I, 272\end{array}$ \\
\hline Average age in years, mean (SD) & $47.3(13.7)$ & $47.8(13.6)$ \\
\hline Age range in years & $18-86$ & $18-85$ \\
\hline \multicolumn{3}{|l|}{ Sex, n (\%) } \\
\hline Female & $282(91.9)$ & $\mathrm{I}, \mathrm{I} 3 \mathrm{I}(88.9)$ \\
\hline \multicolumn{3}{|l|}{ Race, n (\%) } \\
\hline White & $259(84.4)$ & $969(76.2)$ \\
\hline \multicolumn{3}{|l|}{ Language, ${ }^{\mathrm{a}} \mathrm{n}(\%)$} \\
\hline English & $307(100)$ & $\mathrm{I}, 242(97.6)$ \\
\hline Average body mass index, mean (SD) & $27.3(5.3)$ & $28.0(6.0)$ \\
\hline Body mass index range & 18.5 to 46.4 & I5.I to 72.3 \\
\hline \multicolumn{3}{|c|}{ CC Symptom Severity Measures, baseline mean ${ }^{\mathrm{b}}(\mathrm{SD})$} \\
\hline CSBM Frequency & $0.4(0.7)$ & $0.3(0.5)$ \\
\hline SBM Frequency & $2.3(1.5)$ & $2.0(1.6)$ \\
\hline Stool Consistency & $2.4(1.0)$ & $2.4(1.0)$ \\
\hline Straining & $3.1(0.8)$ & $3.2(0.9)$ \\
\hline Bloating & $2.8(0.9)$ & $2.8(0.9)$ \\
\hline Abdominal Discomfort & $2.4(0.9)$ & $2.5(0.8)$ \\
\hline Abdominal Pain & $2.0(0.9)$ & $2.2(0.9)$ \\
\hline Constipation Severity & $3.4(0.8)$ & $3.3(0.7)$ \\
\hline
\end{tabular}

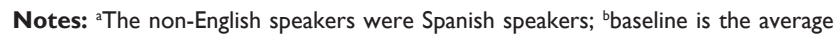
of the pretreatment weeks.

Abbreviations: CC, chronic constipation; CSBM, complete spontaneous bowel movement; SBM, spontaneous bowel movement; SD, standard deviation.

period averages (ie, across 4 weeks in Phase IIb and across 12 weeks in Phase III). As expected, CSBM Frequency, which was used to determine the primary endpoint in the clinical trials, and SBM Frequency correlated strongly ( $r=0.60$ in Phase IIb and $r=0.73$ in Phase III). Stool Consistency correlated moderately to strongly with CSBM Frequency and SBM Frequency ( $r=0.37$ and $r=0.39$, respectively, in Phase IIb; $r=0.43$ and $r=0.46$, respectively, in Phase III). Additionally, it was observed that CSBM Frequency correlated moderately to strongly with Straining, Bloating, Abdominal Discomfort, and Abdominal Pain in both trials.

As hypothesized, Bloating and Abdominal Discomfort correlated strongly with one another in both Phase IIb and Phase III (both $r=0.81$ ). Additionally, Bloating correlated strongly with Abdominal Pain $(r=0.65$ in Phase IIb; $r=0.71$ in Phase III) and Abdominal Discomfort correlated strongly with Abdominal Pain ( $r=0.81$ in Phase IIb; $r=0.90$ in phase III).

Also as hypothesized, Constipation Severity was strongly and negatively associated with CSBM Frequency ( $r=-0.60$ in Phase IIb; $r=-0.59$ in Phase III). Constipation Severity was also strongly and negatively correlated with SBM Frequency ( $r=-0.52$ in Phase IIb; $r=-0.54$ in Phase III) and moderately to strongly correlated with Stool Consistency ( $r=-0.37$ in Phase IIb; $r=-0.49$ in Phase III). Furthermore, Constipation 
Table 2 Inter-item correlations and correlations with Constipation Severity (treatment period averages)

\begin{tabular}{|c|c|c|c|c|c|c|c|}
\hline \multirow{2}{*}{$\begin{array}{l}\text { CC Symptom } \\
\text { Severity Measure }\end{array}$} & \multicolumn{4}{|c|}{ Bowel symptoms } & \multicolumn{3}{|c|}{ Abdominal symptoms } \\
\hline & $\begin{array}{l}\text { CSBM } \\
\text { Frequency }\end{array}$ & $\begin{array}{l}\text { SBM } \\
\text { Frequency }\end{array}$ & $\begin{array}{l}\text { Stool } \\
\text { Consistency }\end{array}$ & Straining & Bloating & $\begin{array}{l}\text { Abdominal } \\
\text { Discomfort }\end{array}$ & $\begin{array}{l}\text { Abdominal } \\
\text { Pain }\end{array}$ \\
\hline \multicolumn{8}{|l|}{ Phase Ilb } \\
\hline \multicolumn{8}{|l|}{ Bowel symptoms } \\
\hline CSBM Frequency & - & & & & & & \\
\hline SBM Frequency & $0.60 *$ & - & & & & & \\
\hline Stool Consistency & $0.37 *$ & $0.39 *$ & - & & & & \\
\hline Straining & $-0.45^{*}$ & $-0.28 *$ & $-0.50^{*}$ & - & & & \\
\hline \multicolumn{8}{|l|}{ Abdominal symptoms } \\
\hline Bloating & $-0.45^{*}$ & $-0.24 *$ & -0.12 & $0.42^{*}$ & - & & \\
\hline Abdominal Discomfort & $-0.42^{*}$ & $-0.23^{*}$ & -0.02 & $0.42^{*}$ & $0.81 *$ & - & \\
\hline Abdominal Pain & $-0.30 *$ & -0.12 & 0.02 & $0.37^{*}$ & $0.65^{*}$ & $0.8 I^{*}$ & - \\
\hline Constipation Severity & $-0.60 *$ & $-0.52^{*}$ & $-0.37^{*}$ & $0.53^{*}$ & $0.58^{*}$ & $0.54 *$ & $0.42 *$ \\
\hline \multicolumn{8}{|l|}{ Phase III } \\
\hline \multicolumn{8}{|l|}{ Bowel symptoms } \\
\hline CSBM Frequency & - & & & & & & \\
\hline SBM Frequency & $0.73 *$ & - & & & & & \\
\hline Stool Consistency & $0.43^{*}$ & $0.46 *$ & - & & & & \\
\hline Straining & $-0.49 *$ & $-0.40^{*}$ & $-0.62^{*}$ & - & & & \\
\hline \multicolumn{8}{|l|}{ Abdominal symptoms } \\
\hline Bloating & $-0.40^{*}$ & $-0.26 *$ & $-0.22^{*}$ & $0.53^{*}$ & - & & \\
\hline Abdominal Discomfort & $-0.33^{*}$ & $-0.21^{*}$ & $-0.18^{*}$ & $0.5 I^{*}$ & $0.8 I^{*}$ & - & \\
\hline Abdominal Pain & $-0.29 *$ & $-0.20 *$ & $-0.16^{*}$ & $0.48^{*}$ & $0.7 I^{*}$ & $0.90 *$ & - \\
\hline Constipation Severity & $-0.59 *$ & $-0.54 *$ & $-0.49 *$ & $0.70^{*}$ & $0.63^{*}$ & $0.59 *$ & $0.52^{*}$ \\
\hline
\end{tabular}

Notes: $* P<0.01$. - signifies not computed.

Abbreviations: CC, chronic constipation; CSBM, complete spontaneous bowel movement; SBM, spontaneous bowel movement.

Severity was strongly and positively associated with Bloating ( $r=0.58$ in Phase IIb; $r=0.63$ in Phase III), Abdominal Discomfort ( $r=0.54$ in Phase IIb; $r=0.59$ in Phase III), and Straining ( $r=0.53$ in Phase IIb; $r=0.70$ in Phase III), as well as with Abdominal Pain in the Phase III trials $(r=0.52)$.
Table 3 displays the correlations between change in CC Symptom Severity Measures and Constipation Relief. The correlations associated with CSBM Frequency, SBM Frequency, and Stool Consistency were negative because lower values for these variables denote worse outcomes;

Table 3 Correlations between Constipation Relief and change in CC Symptom Severity Measures

\begin{tabular}{|c|c|c|c|c|c|c|}
\hline $\begin{array}{l}\text { Change in CC Symptom } \\
\text { Severity Measure }\end{array}$ & BL to week I & BL to week 2 & BL to week 4 & BL to week 8 & BL to week I 2 & $\begin{array}{l}\text { BL to treatment } \\
\text { average }\end{array}$ \\
\hline \multicolumn{7}{|l|}{ Phase Ilb } \\
\hline CSBM Frequency & -0.52 & -0.54 & -0.58 & - & - & -0.59 \\
\hline SBM Frequency & -0.45 & -0.39 & -0.41 & - & - & -0.46 \\
\hline Stool Consistency & -0.38 & -0.36 & -0.51 & - & - & -0.39 \\
\hline Straining & 0.38 & 0.38 & 0.45 & - & - & 0.40 \\
\hline Bloating & 0.36 & 0.43 & 0.40 & - & - & 0.45 \\
\hline Abdominal Discomfort & 0.33 & 0.37 & 0.41 & - & - & 0.43 \\
\hline Abdominal Pain & 0.30 & 0.31 & 0.34 & - & - & 0.37 \\
\hline \multicolumn{7}{|l|}{ Phase III } \\
\hline CSBM Frequency & -0.49 & -0.53 & -0.49 & -0.52 & -0.52 & -0.60 \\
\hline SBM Frequency & -0.39 & -0.48 & -0.45 & -0.43 & -0.46 & -0.51 \\
\hline Stool Consistency & -0.39 & -0.43 & -0.40 & -0.42 & -0.39 & -0.48 \\
\hline Straining & 0.40 & 0.38 & 0.41 & 0.41 & 0.42 & 0.48 \\
\hline Bloating & 0.35 & 0.39 & 0.42 & 0.44 & 0.44 & 0.48 \\
\hline Abdominal Discomfort & 0.29 & 0.36 & 0.36 & 0.40 & 0.44 & 0.43 \\
\hline Abdominal Pain & 0.26 & 0.31 & 0.31 & 0.35 & 0.39 & 0.38 \\
\hline
\end{tabular}

Notes: All correlations are statistically significant $(P<0.00 I)$. - signifies data not available.

Abbreviations: BL, baseline; CC, chronic constipation; CSBM, complete spontaneous bowel movement; SBM, spontaneous bowel movement. 
for the rest of the CC Symptom Severity Measures and Constipation Relief, higher values indicate worse outcomes. While the correlations between Constipation Relief and CSBM Frequency were the strongest, all correlations either approached or exceeded the criterion for moderate $(|r| \geq 0.30)$, and all were statistically significant $(P<0.001)$.

The validity correlations between the changes from baseline in the CC Symptom Severity Measures and changes in the PAC-QOL are shown in Table 4. Change in the CC Symptom Severity Measures pertaining to bowel symptoms was not as strongly correlated with improvement in the PAC-QOL Overall and Physical Discomfort scores as hypothesized. Instead, these correlations tended to be moderate in size, with some large correlations with Straining. The correlations between the changes in PAC-QOL Overall and Physical Discomfort scores and changes in CC Symptom Severity Measures pertaining to abdominal symptoms were mostly large in size $(r>0.50, P<0.01)$, as predicted. Although changes in Psychosocial Discomfort and Worries and Concerns scores were predicted to correlate weakly with changes in CC Symptom Severity Measures, the correlations were somewhat greater than anticipated, but still lower than the correlations observed with PAC-QOL Overall and Physical Discomfort scores. The overall pattern of correlations was consistent with that hypothesized - correlations that were expected to be weak were moderate in size, but were still relatively small compared to correlations that were hypothesized to be strong.

\section{Factor analysis}

The EFA of the Phase IIb treatment period average data yielded eight eigenvalues (in order): 4.009, 1.622, 0.802, $0.403,0.394,0.360,0.281$, and 0.128 . While there are two factors with eigenvalues greater than 1.0, the first factor accounts for $50.11 \%$ of the variance, more than twice as much as the second factor extracted (20.28\%). Still, the two-factor EFA solution yielded the most interpretable solution: one factor consisted of bowel symptoms (SBM Frequency, CSBM Frequency, Stool Consistency, Straining, and Constipation Severity), while the other factor consisted of abdominal symptoms (Bloating, Abdominal Discomfort, and Abdominal Pain). The correlation between the bowel symptoms factor and the abdominal symptoms factor was 0.41 .

When the two-factor EFA model was applied to the pooled Phase III data averaged over the treatment period for the CFA, the CFA solution did not converge because some abdominal symptoms and some bowel symptoms were highly correlated. Modification indices suggested that the unique portions of highly correlated pairs of measures should be allowed to covary. Subsequently, when the error variances of CSBM Frequency and SBM Frequency, Stool Consistency and Straining, and Abdominal Pain and Abdominal Discomfort were correlated, a proper solution was obtained and the model fit was considerably improved (Comparative Fit Index $=0.97$, Tucker-Lewis index $=0.94$, SRMR $=0.06$ ), suggesting that these pairs of PRO measures are more correlated with each other than can be explained by the variance shared with the

Table 4 Correlations between change in PAC-QOL scores and change in CC Symptom Severity Measures

\begin{tabular}{|c|c|c|c|c|c|c|c|}
\hline \multirow[t]{2}{*}{ Phase } & \multicolumn{4}{|c|}{ Bowel symptoms } & \multicolumn{3}{|c|}{ Abdominal symptoms } \\
\hline & $\begin{array}{l}\text { CSBM } \\
\text { Frequency }\end{array}$ & $\begin{array}{l}\text { SBM } \\
\text { Frequency }\end{array}$ & $\begin{array}{l}\text { Stool } \\
\text { Consistency }\end{array}$ & Straining & Bloating & $\begin{array}{l}\text { Abdominal } \\
\text { Discomfort }\end{array}$ & $\begin{array}{l}\text { Abdominal } \\
\text { Pain }\end{array}$ \\
\hline \multicolumn{8}{|c|}{ PAC-QOL overall } \\
\hline Phase Ilb & -0.47 & -0.37 & -0.44 & 0.54 & 0.53 & 0.56 & 0.50 \\
\hline Phase III & -0.43 & -0.40 & -0.33 & 0.46 & 0.57 & 0.57 & 0.53 \\
\hline \multicolumn{8}{|c|}{ Physical Discomfort } \\
\hline Phase Ilb & -0.46 & -0.36 & -0.48 & 0.59 & 0.56 & 0.56 & 0.47 \\
\hline Phase III & -0.42 & -0.37 & -0.32 & 0.45 & 0.63 & 0.61 & 0.56 \\
\hline \multicolumn{8}{|c|}{ Psychosocial Discomfort } \\
\hline Phase Ilb & -0.29 & -0.21 & -0.24 & 0.34 & 0.36 & 0.42 & 0.41 \\
\hline Phase III & -0.26 & -0.23 & -0.18 & 0.31 & 0.42 & 0.42 & 0.40 \\
\hline \multicolumn{8}{|l|}{ Satisfaction } \\
\hline Phase Ilb & -0.52 & -0.48 & -0.48 & 0.47 & 0.47 & 0.44 & 0.37 \\
\hline Phase III & -0.48 & -0.44 & -0.40 & 0.44 & 0.47 & 0.44 & 0.39 \\
\hline \multicolumn{8}{|c|}{ Worries and Concerns } \\
\hline Phase Ilb & -0.35 & -0.25 & -0.32 & 0.46 & 0.44 & 0.50 & 0.45 \\
\hline Phase III & -0.34 & -0.33 & -0.25 & 0.39 & 0.48 & 0.50 & 0.46 \\
\hline
\end{tabular}

Notes: The change in PAC-QOL subscale scores from day I to end of treatment was correlated with the change in the CC Symptom Severity Measures between baseline and the average over the last 2 weeks of treatment. All correlations are statistically significant $(P<0.0 \mathrm{I})$.

Abbreviations: CC, chronic constipation; CSBM, complete spontaneous bowel movement; PAC-QOL, Patient Assessment of Constipation Quality of Life questionnaire; SBM, spontaneous bowel movement. 
factor they load on. Figure 1 displays the factor loadings for the two-factor solution. The correlation between the abdominal symptoms factor and bowel symptoms factor was 0.71 .

\section{Discriminating ability}

Table 5 displays the results of the known-groups comparisons based on Overall CSBM Responder status and the lower and upper levels of Constipation Severity. As predicted, all average scores of responders were statistically significantly better than those of nonresponders. Additionally, the average scores of patients reporting milder constipation symptoms were statistically significantly better than for those patients reporting more severe symptoms.

\section{Responsiveness}

Table 6 displays Guyatt's responsiveness statistics based on Overall CSBM Responder status and Constipation Relief. From the Phase III data, Guyatt's statistics can be characterized as large for the bowel symptom measures, with CSBM Frequency being the largest in both Phase IIb and Phase III trials (3.3 in Phase IIb and 2.7 in Phase III using Overall CSBM Responder, and 6.4 in Phase IIb and 5.3 in Phase III using Constipation Relief). The effect sizes for the abdominal symptom measures were mostly moderate to large, with Bloating being the largest for both Overall CSBM Responder ( -0.7 in Phase IIb and -1.05 in Phase III) and Constipation Relief (-2.0 in Phase IIb and -1.5 in Phase III), indicating that improvement in the responder or improved group is about $1 \mathrm{SD}$ greater than the improvement in the nonresponder or worsened group.

\section{Discussion}

A primary goal of this study was to psychometrically evaluate a set of patient-reported CC Symptom Severity Measures in a Phase IIb study and two Phase III trials designed to assess linaclotide for the treatment of $\mathrm{CC}^{3,4}$ The linaclotide trials were the first to include a comprehensive set of CC Symptom
Severity Measures that were developed in accordance with the FDA PRO guidance ${ }^{2}$ and validated in the appropriate patient population. These CC Symptom Severity Measures were based on extensive patient input and appraised through qualitative interviews supporting their content validity and concept saturation, ${ }^{17}$ and were used as primary and secondary endpoints in the linaclotide studies.

Historically, CC studies have principally described the severity of CC in terms of bowel symptoms (eg, BM frequency, stool consistency, straining), and the Rome diagnostic criteria for functional constipation, ${ }^{18}$ developed to help standardize patient enrollment into clinical trials, reference only those symptoms related to bowel function and stool passage. ${ }^{19}$ However, interviews with $\mathrm{CC}$ patients have shown that abdominal symptoms, such as bloating, discomfort, and pain, are features of CC important to patients. ${ }^{17,20}$ The newly developed CC Symptom Severity Measures used in the linaclotide trials include both abdominal symptom measures (Bloating, Abdominal Discomfort, and Abdominal Pain) and bowel symptom measures (CSBM Frequency, SBM Frequency, Stool Consistency, and Straining).

Both the Phase IIb study and Phase III trials provided solid support for the test-retest reliability and construct validity of the CC Symptom Severity Measures. Correlations hypothesized a priori were directionally correct and generally of the predicted magnitude. Notably, CSBM Frequency, which was used to compute the primary endpoint (CSBM Overall Responder) in Phase III, correlated moderately to strongly with the other bowel symptom measures and mostly moderately with the abdominal symptoms. There were also some extremely large correlations, for example, between Abdominal Discomfort and Abdominal Pain. Such strong correlations indicate potential redundancy and, in the context of multi-item scale construction, would normally afford the opportunity for item deletion. However, decisions about item reduction must be based on the totality of evidence gathered - both quantitative and qualitative results. The PRO guidance recommends that all

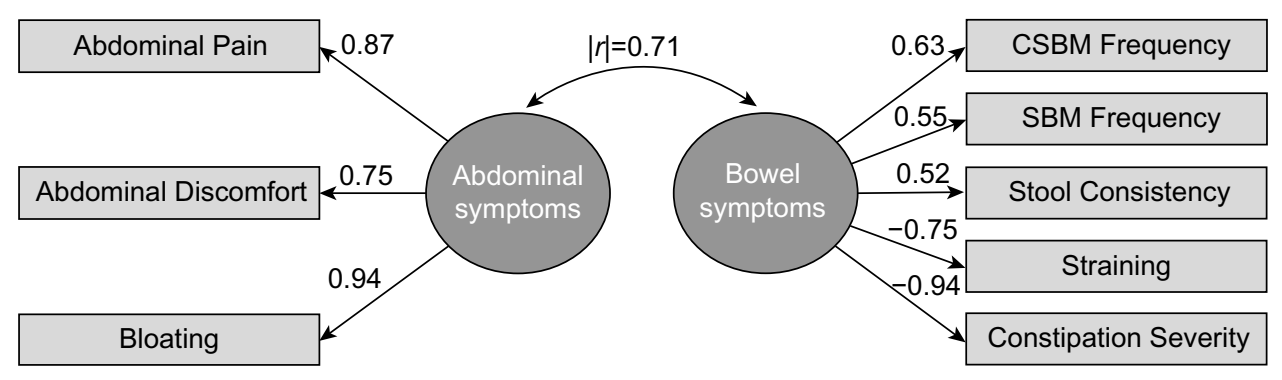

Figure I Illustration of the two-factor confirmatory factor analysis model for CC Symptom Severity Measures, with factor loadings.

Notes: The confirmatory factor analysis solution includes correlated residuals that are not shown between the following: CSBM Frequency and SBM Frequency, Straining and Stool Consistency, Abdominal Pain and Abdominal Discomfort.

Abbreviations: CC, chronic constipation; CSBM, complete spontaneous bowel movement; SBM, spontaneous bowel movement. 
Table 5 Known-groups analyses - subgroup means on CC Symptom Severity Measures (treatment period average)

\begin{tabular}{|c|c|c|c|c|}
\hline \multirow{2}{*}{$\begin{array}{l}\text { CC Symptom } \\
\text { Severity Measures }\end{array}$} & \multicolumn{2}{|c|}{ Overall CSBM known group ${ }^{a}$} & \multicolumn{2}{|c|}{ Constipation Severity known group ${ }^{\mathrm{a}, \mathrm{b}}$} \\
\hline & $\begin{array}{l}\text { Nonresponder, } \\
\text { mean (SD) }\end{array}$ & $\begin{array}{l}\text { Responder, } \\
\text { mean (SD) }\end{array}$ & $\begin{array}{l}\text { Severe/very severe, } \\
\text { mean (SD) }\end{array}$ & $\begin{array}{l}\text { None/mild } \\
\text { mean (SD) }\end{array}$ \\
\hline Phase Ilb & $(n=23 I-238)^{c}$ & $(n=69)$ & $(n=53-56)^{c}$ & $(n=123)$ \\
\hline \multicolumn{5}{|l|}{ Bowel symptoms } \\
\hline CSBM Frequency & $1.2(1.2)$ & $5.4(2.2)$ & $0.5(0.9)$ & $3.5(2.7)$ \\
\hline SBM Frequency & $4.7(2.9)$ & $8.1(3.3)$ & $2.9(2.4)$ & $7.1(3.3)$ \\
\hline Stool Consistency & $3.7(1.5)$ & $4.7(1.0)$ & $3.5(1.6)$ & $4.5(1.2)$ \\
\hline Straining & $2.3(0.8)$ & $1.7(0.5)$ & $2.7(0.9)$ & $1.8(0.6)$ \\
\hline \multicolumn{5}{|l|}{ Abdominal symptoms } \\
\hline Bloating & $2.7(0.9)$ & I.8 (0.6) & $3.2(0.8)$ & $2.0(0.7)$ \\
\hline Abdominal Discomfort & $2.3(0.8)$ & $1.6(0.6)$ & $2.8(0.8)$ & $1.8(0.6)$ \\
\hline Abdominal Pain & $1.9(0.8)$ & $\mathrm{I} .4(0.5)$ & $2.3(0.9)$ & $\mathrm{I} .5(0.6)$ \\
\hline Phase III & $(n=I, 034-I, 087)^{c}$ & $(n=185)$ & $(n=185-200)^{c}$ & $(n=568-583)^{c}$ \\
\hline \multicolumn{5}{|l|}{ Bowel symptoms } \\
\hline CSBM Frequency & $1.2(1.9)$ & $6.3(2.8)$ & $0.3(0.6)$ & $3.3(3.0)$ \\
\hline SBM Frequency & $3.9(3.2)$ & $8.6(3.6)$ & $1.8(1.8)$ & $6.1(3.8)$ \\
\hline Stool Consistency & $3.7(1.3)$ & $4.9(1.0)$ & $3.0(1.3)$ & $4.4(1.2)$ \\
\hline Straining & $2.4(0.8)$ & $1.6(0.5)$ & $3.2(0.9)$ & $1.8(0.5)$ \\
\hline \multicolumn{5}{|l|}{ Abdominal symptoms } \\
\hline Bloating & $2.5(0.8)$ & I.8 (0.6) & $3.2(0.9)$ & $1.9(0.6)$ \\
\hline Abdominal Discomfort & $2.2(0.8)$ & $\mathrm{I} .6(0.5)$ & $2.8(0.9)$ & I.7 (0.5) \\
\hline Abdominal Pain & $1.9(0.8)$ & $\mathrm{I} .4(0.4)$ & $2.4(1.0)$ & $\mathrm{I} .5(0.5)$ \\
\hline
\end{tabular}

Notes: aResponder and nonresponder means are statistically different for all CC Symptom Severity Measures in Phase Ilb and Phase III ( $P<0.00$ I); baveraged across treatment period. Higher mean values represent improvement for CSBM Frequency, SBM Frequency, and Stool Consistency, while lower values represent improvement for Straining, Bloating, Abdominal Discomfort, and Abdominal Pain. 'Subgroup number may vary due to missing data.

Abbreviations: CC, chronic constipation; CSBM, complete spontaneous bowel movement; SBM, spontaneous bowel movement; SD, standard deviation.

symptoms important to patients be measured in order to assure content validity, and $\mathrm{CC}$ patients consistently reported that these were all important and distinguishable components of CC within the context of in-depth qualitative research. Confirming the conceptual model underlying the set of PRO measures, the factor analyses indicated that two highly related factors explain the pattern of correlations among the CC Symptom Severity Measures: one factor included the bowel symptoms, while the

Table 6 Responsiveness analyses - subgroup mean changes on CC Symptom Severity Measures and effect sizes

\begin{tabular}{|c|c|c|c|c|c|c|}
\hline \multirow{2}{*}{$\begin{array}{l}\text { CC Symptom } \\
\text { Severity Measures }\end{array}$} & \multicolumn{3}{|c|}{ Overall CSBM Responder status } & \multicolumn{3}{|c|}{ Constipation Relief ${ }^{a}$} \\
\hline & $\begin{array}{l}\text { Nonresponder, } \\
\text { mean (SD) }\end{array}$ & $\begin{array}{l}\text { Responder, } \\
\text { mean (SD) }\end{array}$ & $\begin{array}{l}\text { Guyatt's statistic } \\
\text { (effect size) }\end{array}$ & $\begin{array}{l}\text { Worsened, } \\
\text { mean (SD) }\end{array}$ & $\begin{array}{l}\text { Improved, } \\
\text { mean (SD) }\end{array}$ & $\begin{array}{l}\text { Guyatt's statistic } \\
\text { (effect size) }\end{array}$ \\
\hline Phase Ilb & $(n=23 I-238)^{b}$ & $(n=69)$ & & $(n=12-19)^{b}$ & $(n=82-87)^{b}$ & \\
\hline CSBM Frequency & $0.82(1.20)$ & $4.77(2.31)$ & 3.29 & $0.15(0.55)$ & $3.67(2.52)$ & 6.36 \\
\hline SBM Frequency & $2.52(2.67)$ & $5.59(3.53)$ & 1.14 & $1.85(3.10)$ & $5.28(3.35)$ & I.II \\
\hline Stool Consistency & $1.20(1.42)$ & $2.47(1.24)$ & 0.89 & $1.10(1.86)$ & $2.36(1.30)$ & 0.68 \\
\hline Straining & $-0.75(0.94)$ & $-1.55(0.84)$ & -0.86 & $-0.57(1.34)$ & $-1.53(0.87)$ & -0.72 \\
\hline Bloating & $-0.19(0.64)$ & $-0.67(0.65)$ & -0.74 & $0.22(0.45)$ & $-0.69(0.67)$ & -2.02 \\
\hline Abdominal Discomfort & $-0.18(0.66)$ & $-0.53(0.70)$ & -0.54 & $0.34(0.50)$ & $-0.60(0.68)$ & -1.88 \\
\hline Abdominal Pain & $-0.19(0.62)$ & $-0.39(0.68)$ & -0.31 & $0.27(0.5 \mathrm{I})$ & $-0.52(0.69)$ & -1.57 \\
\hline Phase III & $(n=1,034-1,087)^{b}$ & $(n=185)$ & & $(n=47-70)^{b}$ & $(n=382-424)^{b}$ & \\
\hline CSBM Frequency & $0.97(1.80)$ & $5.80(2.9 I)$ & 2.68 & $0.19(0.63)$ & $3.54(3.16)$ & 5.34 \\
\hline SBM Frequency & $2.00(2.94)$ & $6.14(3.54)$ & $\mathrm{I} .4 \mathrm{I}$ & $0.65(2.26)$ & $4.48(3.72)$ & 1.69 \\
\hline Stool Consistency & $1.28(1.37)$ & $2.36(1.23)$ & 0.79 & $0.51(1.05)$ & $2.18(1.35)$ & 1.59 \\
\hline Straining & $-0.84(0.90)$ & $-1.59(0.87)$ & -0.83 & $-0.20(0.67)$ & $-1.45(0.88)$ & -1.89 \\
\hline Bloating & $-0.28(0.59)$ & $-0.90(0.69)$ & -1.05 & $-0.05(0.47)$ & $-0.76(0.69)$ & $-|.5|$ \\
\hline Abdominal Discomfort & $-0.34(0.56)$ & $-0.91(0.70)$ & -1.02 & $-0.02(0.49)$ & $-0.75(0.69)$ & -1.50 \\
\hline Abdominal Pain & $-0.31(0.53)$ & $-0.77(0.7 \mathrm{I})$ & -0.87 & $-0.07(0.47)$ & $-0.66(0.66)$ & 1.26 \\
\hline
\end{tabular}

Notes: almproved = completely relieved or considerably relieved; worsened = somewhat worse, considerably worse, or "as bad as I can imagine". Higher mean values represent improvement for CSBM Frequency, SBM Frequency, and Stool Consistency, while lower values represent improvement for Straining, Bloating, Abdominal Discomfort, and Abdominal Pain. Change is computed as treatment period average minus baseline, and mean difference is computed as responder minus nonresponder; therefore, effect sizes associated with CSBM Frequency, SBM Frequency, and Stool Consistency are positive, and effect sizes associated with Straining, Bloating, Abdominal Discomfort, and Abdominal Pain are negative. 'Subgroup number may vary due to missing data.

Abbreviations: CC, chronic constipation; CSBM, complete spontaneous bowel movement; SBM, spontaneous bowel movement; SD, standard deviation. 
other included the abdominal symptoms. While Constipation Severity theoretically encompasses both sets of symptoms, it appears to be driven largely by patients' perceptions of their bowel symptoms. Responsiveness statistics were generally moderate to strong for the CC Symptom Severity Measures in both the Phase IIb study and Phase III clinical trials, indicating that these measures are capable of detecting change.

This study builds on the qualitative evidence for the CC Symptom Severity Measures ${ }^{17}$ and provides empirical support for the measurement of both abdominal symptoms and bowel symptoms in CC in the context of a longitudinal clinical trial. Although the abdominal symptoms reported by CC patients were generally mild (Abdominal Pain) to moderate (Bloating) at baseline, the average severity of abdominal symptoms improved with treatment, and differences in average abdominal symptom severity were observed between treatment responders and nonresponders. In addition, this study provides support for the possibility of creating $\mathrm{CC}$ bowel and abdominal symptom composite scores that may have considerable clinical utility and also allow the detection of a differential treatment impact. For example, some agents may improve stool frequency and consistency but not have a significant impact on abdominal symptoms. It would be important for such information to be available to physicians, patients, and other stakeholders. Additional work would be required to evaluate the feasibility of separate bowel and abdominal symptoms composite scores, as well as the reliability and validity of such composite scores.

\section{Conclusion}

The results of these analyses demonstrate that the CC Symptom Severity Measures are reliable, valid, and responsive in a CC population. Ensuring the measures used to develop endpoints have strong psychometric properties supports the conclusion of a significant treatment benefit for linaclotide ${ }^{3,4}$ in the primary bowel symptom endpoint and all key secondary bowel and abdominal symptom endpoints in the linaclotide trials.

\section{Acknowledgement}

The authors thank Cheryl Coon for her assistance with the factor analysis.

\section{Disclosure}

Caroline B Kurtz and Jeffrey M Johnston are employees of Ironwood Pharmaceuticals, Inc. and own stock/stock options in Ironwood Pharmaceuticals, Inc. Mollie J Baird and James MacDougall were employees of Ironwood Pharmaceuticals, Inc. while these analyses were conducted. Robyn T Carson and Stavros Tourkodimitris are employees of Forest Laboratories,
Inc. and own stock/stock options in Forest Laboratories, Inc. Valerie SL Williams, Lauren M Nelson, and Sheri E Fehnel are paid consultants to Ironwood Pharmaceuticals, Inc. and Forest Laboratories, Inc. Forest Research Institute and Ironwood Pharmaceuticals provided funding for this study. The authors report no other conflicts of interest in this work.

\section{References}

1. Higgins PD, Johanson JF. Epidemiology of constipation in North America: a systematic review. Am J Gastroenterol. 2004;99:750-759.

2. Guidance for Industry. Patient-Reported Outcome Measures: Use in Medical Product Development to Support Labeling Claims. US Department of Health and Human Services, Food and Drug Administration, Center for Drug Evaluation and Research (CDER), Center for Biologics Evaluation and Research (CBER), Center for Devices and Radiological Health (CDRH); 2009. Available from: http:/ www.fda.gov/downloads/Drugs/GuidanceComplianceRegulatoryInformation/Guidances/UCM193282.pdf. Accessed March 24, 2010.

3. Lembo AJ, Kurtz CB, Macdougall JE, et al. Efficacy of linaclotide for patients with chronic constipation. Gastroenterology. 2010;138: 886-895.

4. Lembo AJ, Schneier HA, Shiff SJ, et al. Two randomized trials of linaclotide for chronic constipation. N Engl J Med. 2011;365:527-536.

5. Linzess [prescribing information]. St.Louis, MO: Forest Pharmaceuticals, Inc., and Cambridge, MA: Ironwood Pharmaceuticals, Inc. August 2014. Available from: http://www.accessdata.fda.gov/drugsatfda_docs/ label/2012/202811s0001bl.pdf. Accessed August 4, 2014.

6. Heaton KW, O'Donnell LJ. An office guide to whole-gut transit time. Patients' recollection of their stool form. J Clin Gastroenterol. 1994;19(1):28-30.

7. Marquis P, De La Loge C, Dubois D, McDermott A, Chassany O. Development and validation of the Patient Assessment of Constipation Quality Of Life questionnaire. Scand J Gastroenterol. 2005;40: 540-551.

8. Muthén LK, Muthén BO. Mplus User's Guide. 6th ed. Los Angeles: Muthén \& Muthén; 1998-2010.

9. Nunnally JC, Bernstein IH. Psychometric Theory. 3rd ed. New York: McGraw-Hill; 1994

10. Cohen J. Statistical Power Analysis for the Behavioral Sciences. 2nd ed. Hillsdale, NJ: Lawrence Erlbaum Associates; 1988.

11. Kaiser H. The application of electronic computers to factor analysis. Educ Psychol Meas. 1960;20:141-151.

12. Jöreskog KG, Sörbom D. LISREL VI: Analysis of Linear Structural Relationships by Maximum Likelihood and Least Squares Methods. Mooresville, IN: Scientific Software, Inc.; 1984.

13. Bentler PM. EQS Structural Equations Program Manual. Los Angeles, CA: BMDP Statistical Software; 1989.

14. Tucker LR, Lewis C. A reliability coefficient for maximum likelihood factor analysis. Psychometrika. 1973;38:1-10.

15. Hu L, Bentler PM. Cutoff criteria for fit indexes in covariance structure analysis: conventional criteria versus new alternatives. Struct Equ Modeling. 1999;6:1-55.

16. Guyatt G, Walter S, Norman G. Measuring change over time: assessing the usefulness of evaluative instruments. J Chronic Dis. 1987;40:171-178.

17. Ervin CM, Fehnel SE, Baird MJ, et al. Assessment of treatment response in chronic constipation clinical trials. Clin Exp Gastroenterol. 2014; 7:191-198.

18. Drossman DA, Corazziari E, Talley NJ, Thompson WG, Whitehead WE, editors. Rome II: The Functional Gastrointestinal Disorders. 2nd ed. McLean, VA: Degnon Associates; 2000.

19. Longstreth GF, Thompson WG, Chey WD, Houghton LA, Mearin F, Spiller RC. Functional bowel disorders. Gastroenterology. 2006;130: 1480-1491.

20. Johanson JF, Kralstein J. Chronic constipation: a survey of the patient perspective. Aliment Pharmacol Ther. 2007;25:599-608. 


\section{Publish your work in this journal}

Clinical and Experimental Gastroenterology is an international, peerreviewed, open access journal, publishing all aspects of gastroenterology in the clinic and laboratory, including: Pathology, pathophysiology of gastrointestinal disease; Investigation and treatment of gastointestinal disease; Pharmacology of drugs used in the alimentary tract;
Immunology/genetics/genomics related to gastrointestinal disease. This journal is indexed on CAS. The manuscript management system is completely online and includes a very quick and fair peer-review system. Visit http://www.dovepress.com/testimonials.php to read real quotes from published authors.

Submit your manuscript here: http://www.dovepress.com/clinical-and-experimental-gastroenterology-journal 